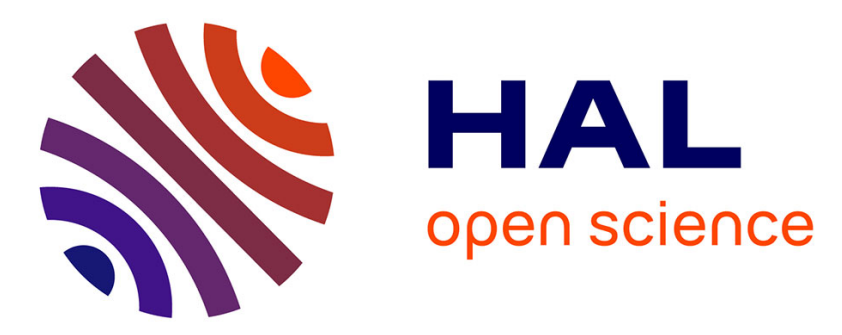

\title{
Thermal, conformational and rheological properties of $\kappa$-carrageenan-sodium stearoyl lactylate gels and solutions
}

\author{
M.C. Ortiz-Tafoya, Agnès Rolland-Sabaté, Catherine Garnier, Josefina \\ Valadez-García, Alberto Tecante
}

\section{To cite this version:}

M.C. Ortiz-Tafoya, Agnès Rolland-Sabaté, Catherine Garnier, Josefina Valadez-García, Alberto Tecante. Thermal, conformational and rheological properties of $\kappa$-carrageenan-sodium stearoyl lactylate gels and solutions. Carbohydrate Polymers, 2018, 193, pp.289-297. 10.1016/j.carbpol.2018.04.002 . hal-02621202

\section{HAL Id: hal-02621202 \\ https://hal.inrae.fr/hal-02621202}

Submitted on 26 May 2020

HAL is a multi-disciplinary open access archive for the deposit and dissemination of scientific research documents, whether they are published or not. The documents may come from teaching and research institutions in France or abroad, or from public or private research centers.
L'archive ouverte pluridisciplinaire HAL, est destinée au dépôt et à la diffusion de documents scientifiques de niveau recherche, publiés ou non, émanant des établissements d'enseignement et de recherche français ou étrangers, des laboratoires publics ou privés. 


\title{
Thermal, conformational and rheological properties of $\kappa$-carrageenan- sodium stearoyl lactylate gels and solutions
}

\author{
M.C. Ortiz-Tafoya ${ }^{\mathrm{a}}$, Agnès Rolland-Sabaté ${ }^{\mathrm{b}, \mathrm{c}}$, Catherine Garnier ${ }^{\mathrm{b}}$, Josefina Valadez-García ${ }^{\mathrm{d}}$, \\ Alberto Tecante ${ }^{\mathrm{a}, *}$ \\ ${ }^{a}$ Departamento de Alimentos y Biotecnología, Facultad de Química, Universidad Nacional Autónoma de México, Ciudad Universitaria, CdMx, 04510, Mexico \\ ${ }^{\mathrm{b}}$ UR1268, INRA, Biopolymères Interactions Assemblages, F-44316 Nantes, France \\ c UMR408 Sécurité et Qualité des Produits d'Origine Végétale, INRA, Université Avignon, F-84000, Avignon, France \\ ' Departamento de Bioquímica, Facultad de Medicina, Universidad Nacional Autónoma de México, Ciudad Universitaria, CdMx, 04510, Mexico
}

Keywords:

Carrageenan

DSC

Rheology

Surfactant

Sodium stearoyl lactylate

\begin{abstract}
A B S T R A C T
Polysaccharide-surfactant blends are widely used in foods. However, their possible mutual interactions have not been extensively studied. The purpose of this work was to examine how the anionic surfactant sodium stearoyl lactylate (SSL) affects different properties of $\kappa$-carrageenan solutions and gels. Rheometry, differential scanning calorimetry, asymmetrical flow field-flow fractionation coupled with multiangle laser light scattering, among others, were used to determine the flow and viscoelastic behavior, thermal transitions, and conformation changes, respectively. Interference caused by SSL is postulated as the primary factor to explain the variations in the conformation of $\kappa$-carrageenan in gels and solutions. However, electrostatic repulsions between $\kappa$-carrageenan and SSL can also be involved. These latter interactions are more important for high SSL concentrations $\left(13 \mathrm{mmol} \mathrm{dm}^{-3}\right)$ without addition of $\mathrm{KCl}$, because of the higher net negative charge density of the system. SSL significantly modifies the properties of $\kappa$-carrageenan in aqueous media.
\end{abstract}

\section{Introduction}

Polysaccharides and surfactants are used in dairy, meat and bakery products, among others, to stabilize emulsions and foams. Interactions between surfactants, proteins, and polysaccharides are of paramount importance in food and non-food applications. Research has primarily focused on mixtures of proteins and surfactants and to a lesser extent on blends of polysaccharides and non-food surfactants. Mixtures of chitosan with nonionic and anionic surfactants have been amply studied. Interactions between chitosan and nonionic surfactants like sorbitan monolaurate, sorbitan monooleate, sorbitan trioleate, octaethyleneglycol and mono $n$-dodecyl ether are weak and depend on the chitosan-surfactant concentration and chain length of surfactant (Chiappisi \& Gradzielski, 2015; Grant, Cho, \& Allen, 2006). Interactions between chitosan and anionic sulfated surfactants like sodium dodecyl sulfate, sodium lauryl ether sulfate, and sodium taurocholate are governed by hydrophobic interactions, although electrostatic interactions can also be present. Hydrogen bonds between chitosan and fatty acids can also exist, but hydrophobic interactions are more significant in the final behavior of these mixtures because of the contribution of the hydrocarbon chain of the acids. The degree of ionization of chitosan and fatty acids changes with $\mathrm{pH}$, and therefore these interactions are also $\mathrm{pH}$ dependent (Chiappisi \& Gradzielski, 2015).

Mixtures of carrageenans with different surfactants have been studied to a lesser extent. $\kappa, 1$, and $\lambda$ carrageenans mixed with cationic surfactants like N-dodecyl pyridinium chloride, N-cetylpyridinium chloride, and dodecyl ammonium chloride have been investigated. The type of carrageenan and surfactant concentration determine the behavior of the polysaccharide-surfactant complexes (Kogej, 2008), but it is mainly governed by electrostatic repulsions between oppositely charged species (Vinceković, Katona, Bujan, \& Sovilj, 2011). However, the role of the physical characteristics of the polysaccharides in general, like molar mass, the degree of branching, charge density, the rigidity of the chain, and polar group and chain length of surfactants, should be examined. It is also essential to know the impact of the sol-gel-sol transition temperatures and the sensitivity of the polysaccharide to mono or divalent ions. All this knowledge would facilitate the development of new and more stable products and create the conditions for the components to express their functionalities (Bouyer, Mekhloufi, Rosilio, Grossiord, \& Agnely, 2012).

$\kappa$-carrageenan is a sulfated D-galactan polysaccharide. Its primary structure consists of a repeating disaccharide of alternate $(1 \rightarrow 3)$

\footnotetext{
* Corresponding author.

E-mail address: tecante@unam.mx (A. Tecante).
} 
$\beta$ - D-galactose-4-sulfate and $(1 \rightarrow 4) \alpha$-3,6-anhydro-D-galactose. It is used in the food industry as a stabilizer and gelling agent. Its gels are stiff, brittle, exhibit syneresis and thermal hysteresis. Gelation occurs when hot solutions are cooled and involves a coil-helix transition followed by helix aggregation (De Ruiter \& Rudolph, 1997). The coil to double helix transition is the key step for gelation to occur. Moreover, gelation is very sensitive to salts and can be controlled by the presence of specific cations like $\mathrm{K}^{+}, \mathrm{Cs}^{+}$, and $\mathrm{Rb}^{+}$, since they increase the double helix stability and mediate helix-helix aggregation. Double helix aggregation occurs at a critical temperature, and its value depends on concentration and type of cation present (Rochas \& Rinaudo, 1984).

Sodium stearoyl lactylate (SSL) is an anionic surfactant synthesized from fatty acids and lactic acid in the presence of sodium (Boutte \& Skogerson, 2004). It is formed by a hydrophilic charged head coming from ionic lactic acid and a long hydrophobic hydrocarbon tail from stearic acid (Grigoriev, Leser, Michel, \& Miller, 2007). Commercial SSL is mainly a mixture of $50 \%$ stearoyl-1-lactylate (SSL1), $20 \%$ stearoyl-2lactylate (SSL2), and 5\% stearoyl-3-lactylate (SSL3) (Boutte \& Skogerson, 2004). SSL is widely used in the food industry as an emulsifier in meat products, and as a whipping agent and softener in bakery products (Zinoviadou, Moschakis, Kiosseoglou, \& Biliaderis, 2011). All the components of SSL exhibit different interfacial activities; as an example, the larger hydrophilic head group of SSL2 makes it less surface active than SSL1 (Grigoriev, Leser, Michel, \& Miller, 2006).

The goal of this work was to determine how SSL, a surfactant approved for food use, affects the conformation and physicochemical properties of $\kappa$-carrageenan. The information obtained will serve to understand the behavior of polysaccharide-surfactant mixtures to use it in the development of more complex systems.

\section{Materials and methods}

Food-grade $\kappa$-carrageenan (Ingredients Solutions, USA) was used without further purification. Its molar mass (see Section 2.4) was 308 $366 \mathrm{~g} \mathrm{~mol}^{-1}$. Its potassium, sodium, calcium and magnesium contents determined by atomic absorption spectroscopy were 62 100, 21 513, 1301 and $5.2 \mathrm{ppm}$, respectively. $\mathrm{KCl}$ (Merck, Mexico) and $\mathrm{NaCl}$ (AppliChem, Germany) were reagent grade. Food-grade sodium stearoyl lactylate (SSL, CAS: 25383-99-7; EC: 246-929-7; Palsgaard, Denmark) was used with potassium, sodium, calcium and magnesium contents of 1230, 21 710, 118 and $1.4 \mathrm{ppm}$, respectively; and a measured critical micellar concentration (CMC) of $0.893 \mathrm{mmol} \mathrm{dm}^{-3}$. Deionized water was used in all experiments.

\subsection{Preparation of $\kappa$-carrageenan solutions and gels}

$\kappa$-carrageenan was dispersed in deionized water under stirring for $30 \mathrm{~min}$ at room temperature. After complete dispersion, the surfactant was added to obtain concentrations of $0-1.0 \%(\mathrm{~g} / 100 \mathrm{~g})$, and the mixture was stirred for $15 \mathrm{~min}$ more. Next, the mixture was heated to $92{ }^{\circ} \mathrm{C}$ for $10 \mathrm{~min}$. The hot solutions were cooled to $50^{\circ} \mathrm{C}$. Evaporative losses were compensated by the addition of deionized water. In systems with $\mathrm{KCl}$, the salt was added when the temperature reached $92{ }^{\circ} \mathrm{C}$. In this case, gels were formed on cooling.

\subsection{Differential scanning calorimetry (DSC)}

The thermal transitions of $0.5 \% \kappa$-carrageenan gels and solutions were determined using a microcalorimeter ( $\mu$ DSC 7 Evo, Setaram, France). A mass of $600 \pm 10 \mathrm{mg}$ of sample was weighed into a Hastelloy cell. The reference cell contained an equivalent mass of sample solvent. Both cells were equilibrated for $30 \mathrm{~min}$ and then heated from 5 to $80^{\circ} \mathrm{C}$, held at $80^{\circ} \mathrm{C}$ for $10 \mathrm{~min}$, cooled at $5{ }^{\circ} \mathrm{C}$, and kept at this temperature for $10 \mathrm{~min}$, in three heating-cooling cycles. The heating and cooling rates were $0.8^{\circ} \mathrm{C} \mathrm{min}{ }^{-1}$. Melting and gelation temperatures and enthalpies were determined with commercial software (OriginPro
9.1, OriginLab Corporation, USA). Enthalpies were expressed in $\mathrm{Jg}^{-1}$ of dry matter.

\subsection{Zeta potential}

Zeta potentials of $\kappa$-carrageenan solutions and their blends with SSL were measured at $20^{\circ} \mathrm{C}$ with a Zeta Meter $3.0+$ (Zeta-Meter, Inc., USA) equipped with a microprocessor unit. $\kappa$-carrageenan solutions were diluted to $0.1 \%(\mathrm{w} / \mathrm{w})$. Blends with surfactant were diluted to $0.01 \%$ (w/w) SSL. pH was measured at $20^{\circ} \mathrm{C}$ with a potentiometer (Thermo Scientific Orion, model 420A, Cole-Parmer, USA). The sample was placed in a cell, and electrophoretic mobility of charged particles was measured by tracking their displacement in an electric field with a stereoscopic microscope. Zeta potential $(\mathrm{mV})$ was calculated by the microprocessor unit. Average values obtained by tracking at least twenty different particles are reported.

\subsection{Asymmetrical flow field-flow fractionation coupled with multiangle laser light scattering (AF4-MALLS)}

Molar mass, size, and conformation were analyzed by AF4-MALLS. The AF4 channel flow, cross flow, sample injection and focus flow were controlled with a Wyatt Eclipse AF4 flow chassis (Wyatt Technology Corporation, Santa Barbara, USA), a pump and an autosampler (ThermoFisher Scientific; Waltham, MA, USA). The sample was introduced at $25^{\circ} \mathrm{C}$ into a $275 \mathrm{~mm}$ long trapezoidal channel equipped with a spacer of $350 \mu \mathrm{m}$ thickness and a regenerated cellulose membrane with a nominal cut-off of $10 \mathrm{kDa}$ (Millipore, Bedford, MA, USA). The on-line detectors included a MALLS unit (Dawn ${ }^{\circ}$ HELEOS $^{\mathrm{TM}}$ ) fitted with a K5 flow cell and a He-Ne laser $(\lambda=658 \mathrm{~nm})$, and a refractometer (Optilab T-rEX) operating at the same wavelength (Wyatt Technology Corporation). $\kappa$-carrageenan concentrations were 0.15 and $0.05 \%$ for samples without and with SSL, respectively. All samples were filtered through a $0.45 \mu \mathrm{m}$ membrane (Millipore) before injection. Injection volumes were 65 and $100 \mu \mathrm{L}$ of $\kappa$-carrageenan solutions or mixtures with the surfactant, respectively. The carrier, $100 \mathrm{mmol} \mathrm{dm}^{-3}$ $\mathrm{NaCl}$ (Millipore), was filtered through a $0.1 \mu \mathrm{m}$ membrane (Millipore) and eluted initially at $1 \mathrm{~mL} \mathrm{~min}^{-1}$ in the channel. $\kappa$-carrageenan samples were eluted following a procedure adapted from Bourgoin, Zablackis, \& Poli (2008). The cross-flow was set to $0.8 \mathrm{~mL} \mathrm{~min}^{-1}$ and the sample was injected at $0.20 \mathrm{~mL} \mathrm{~min}^{-1}$ for $300 \mathrm{~s}$. After injection, the sample was left to relax and focus on $120 \mathrm{~s}$. The carrier flow was set to $1 \mathrm{~mL} \mathrm{~min}^{-1}$ for elution, and the cross flow decreased from $0.8 \mathrm{~mL} \mathrm{~min}^{-1}$ to $0.05 \mathrm{~mL} \mathrm{~min}^{-1}$ for $40 \mathrm{~min}$, maintained at this value for $3 \mathrm{~min}$, and finally kept at $0 \mathrm{~mL} \mathrm{~min}^{-1}$ for $2 \mathrm{~min}$. Elution recovery rates were calculated from the ratio of the mass eluted from the channel, given by the integration of the differential refractive index signal, and the injected mass. The latter was obtained from the exact concentration in the injected samples determined by desiccation of $5 \mathrm{~g}$ of sample at $100{ }^{\circ} \mathrm{C}$ for $24 \mathrm{~h}$.

The number-average molar mass, $\overline{M_{n}}$, the weight-average molar mass, $\overline{M_{w}}$, the dispersity, $\overline{M_{w}} / \overline{M_{n}}$, and the z-average radius of gyration (nm), $\bar{R}_{G}$, were obtained with ASTRA ${ }^{\oplus}$ software (Wyatt Technology Corporation; version 6.1.2.84 for PC) as previously described for other polysaccharides (Rolland-Sabaté, Colonna, Mendez-Montealvo, \& Planchot, 2007; Rolland-Sabaté, Guilois, Jaillais, \& Colonna, 2011). The refractive index increment, $\mathrm{dn} / \mathrm{dc}$, for glucans was $0.146 \mathrm{~mL} \mathrm{~g}^{-1}$. The molar mass and radius of gyration of the $i^{\text {th }}$ slice, $M_{i}$, and $R_{G i}$, respectively, were obtained for each slice of the chromatogram peak using the Berry extrapolation with a first order polynomial fit of the light scattered to zero angle.

\subsection{Atomic force microscopy (AFM)}

א-carrageenan gels and its mixtures with 0.5 and $1.0 \%$ SSL were prepared as described in 2.1. Before cooling, they were diluted with hot 
Version définitive du manuscrit publiée dans / Final version of the manuscript published in :

Carbohydrate Polymers (2018), Vol. 193, p. 289-297, DOI: 10.1016/j.carbpol.2018.04.002

Journal homepage : http://www.elsevier.com/locate/carbpol

$\left(85^{\circ} \mathrm{C}\right.$ ) deionized water to a final concentration of $20 \mu \mathrm{g} \mathrm{m}^{-1}$. A $0.04 \%$ (w/w) SSL solution was prepared in water at $55^{\circ} \mathrm{C}$ under mechanical stirring and was not diluted. Aliquots of $5 \mu \mathrm{L}$ of each sample were deposited on mica (diameter $20 \mathrm{~mm}$ ), then onto a magnetic disc, dried at room temperature and relative humidity for at least $30 \mathrm{~min}$, and observed. Each sample was scanned over an area of $10 \mu \mathrm{m}^{2}$ at a rate of $1 \mathrm{~Hz}$ and 256 lines in an Innova Scanning Probe microscope (Veeco Intruments Inc., USA) equipped with a Nanodrive 8.02 controller. The tapping mode was employed using a scanning probe (RTESPA-CP; Bruker, USA) with a constant force and a resonance frequency of $40 \mathrm{~N} \mathrm{~m}^{-1}$ and $300 \mathrm{kHz}$, respectively. Imaging was made at room conditions. AFM data were processed with the Nanoscope Analysis 1.40 software (Bruker, USA) and edited with the Gwyddion 2.49 software (Czech Republic).

\subsection{Rheometry}

Rheological properties were determined using a rotational rheometer (ARES-RFS III, TA Instruments, USA). Flow curves of $\kappa$-carrageenan solutions without $\mathrm{KCl}$ were obtained from $0.01-100 \mathrm{~s}^{-1}$ at $25^{\circ} \mathrm{C}$ in a cone-plate fixture, $50 \mathrm{~mm}$ in diameter, cone angle $2.3^{\circ}$ (0.04 rad) and $40.6 \mu \mathrm{m}$ gap. Viscoelastic properties of gels with $\mathrm{KCl}$ and solutions were determined under low-amplitude oscillatory shear from $0.1-100 \mathrm{rad} \mathrm{s}^{-1}$ at $25^{\circ} \mathrm{C}$ using serrated parallel plates, $25 \mathrm{~mm}$ in diameter, $3 \mathrm{~mm}$ gap. The zone of linear viscoelasticity was established from strain sweeps at $6.28 \mathrm{rad} \cdot \mathrm{s}^{-1}$. Solutions were stored at $4{ }^{\circ} \mathrm{C}$ at least $18 \mathrm{~h}$ before the rheological measurements. The dependence of the dynamic moduli G' and G" with angular frequency, $\omega$, was determined by power-law relationships of the type G' $\alpha \omega \alpha$ and G" $\alpha \omega \beta$.

\subsection{Statistical analysis}

All measurements were made in triplicate. A one-way ANOVA was done with commercial software (Microsoft ${ }^{\circledR}$ Office Excel $^{\circledR}$ 2007, 12.0.6750.5000). Differences between treatment means were obtained by Fisher's least significant difference (LSD) procedure, using Eq. (1).

$L S D=t \sqrt{\frac{2 M S_{E}}{n}}$

In this equation, $\mathrm{t}$ is the Student's t-distribution percentile based on the error degrees of freedom at $\alpha=0.05$ level of significance, $n$ is the number of scores in each treatment sample, and $\mathrm{MS}_{\mathrm{E}}$ is the mean squared error for the ANOVA.

\section{Results and discussion}

\subsection{DSC thermal behavior}

\subsubsection{Gelation and melting in the presence of SSL and $\mathrm{KCl}$}

DSC experiments allowed obtaining the transition temperatures, melting enthalpy, $\Delta \mathrm{H}_{\mathrm{m}}$, and the absolute value of gelation enthalpy, $\left|\Delta \mathrm{H}_{\mathrm{g}}\right|$, of $\kappa$-carrageenan chains in the presence and absence of potassium ions. All these parameters decreased with the increase in SSL concentration as shown in Fig. 1.

The transition temperatures $\left(\mathrm{T}_{\mathrm{m}}=39.8^{\circ} \mathrm{C} ; \mathrm{T}_{\mathrm{g}}=28.0^{\circ} \mathrm{C}\right)$, and enthalpies $\left(\Delta \mathrm{H}_{\mathrm{m}}=36.1 \mathrm{~J} \mathrm{~g}^{-1} ; \Delta \mathrm{H}_{\mathrm{g}}=33.9 \mathrm{~J} \mathrm{~g}^{-1}\right)$ of $\kappa$-carrageenan gels were similar to those previously reported (Núñez-Santiago \& Tecante, 2007). The melting and gelation enthalpies were similar, showing that comparable energy was required for double helix aggregation and melting of the aggregates. Thermal hysteresis, i.e., $\mathrm{T}_{\mathrm{m}}>\mathrm{T}_{\mathrm{g}}$, similar to that observed by Gekko, Mugishima, \& Koga (1987) was present. They observed a difference of $10^{\circ} \mathrm{C}$ between melting and gelation transitions in mixtures of $\kappa$-carrageenan with $25 \mathrm{mmol} \mathrm{dm}^{-3} \mathrm{KCl}$. This result was attributed to the cooperative nature of gelation, i.e., the formation of the first helix facilitates the development of new helices. Thermal hysteresis has been associated with helices aggregation above a total ionic concentration, $\mathrm{C}^{*}$, of $7 \mathrm{mmol} \mathrm{dm}^{-3}$. Below this concentration, this effect is not observed because only a coil-helix transition takes place (Núñez-Santiago \& Tecante, 2007).

The addition of SSL decreased the transition temperatures of gels as shown in Fig. 1a. However, melting exhibited three different zones; 1, 2 , and 3 , for concentration ranges of $0-5.3,5.3-11$, and $11-27 \mathrm{mmol} \mathrm{dm}^{-3}$, respectively. The gelation temperatures had a single-slope linear decrease for $0-27 \mathrm{mmol} \mathrm{dm}^{-3}$ SSL. The linear correlations are given by Eqs. (2)-(5) with $\mathrm{C}_{\mathrm{SSL}}$ units as shown in Fig. 1, the slope in ${ }^{\circ} \mathrm{C} \mathrm{dm}^{3} \mathrm{~mol}^{-1}$, and the ordinate in ${ }^{\circ} \mathrm{C}$.

Melting

Zone1 $T_{m_{1}}=-443 C_{S S L}+39.8 \quad \mathrm{r}=0.9834$

Zone2 $T_{m_{2}}=-174 C_{S S L}+38.5 \mathrm{r}=0.9941$

Zone3 $T_{m_{3}}=-93.5 C_{S S L}+37.4 \mathrm{r}=0.9547$

Gelling

Zone1 $T_{g_{1}}=-123 C_{S S L}+28.0 \mathrm{r}=0.9989$

The rate of decline of transition enthalpies was linear but depended on the range of surfactant concentration. $\Delta \mathrm{H}_{\mathrm{m}}$ decreased seven times faster in the range of $0-5.3 \mathrm{mmol} \mathrm{dm}^{-3}$ (Zone 1) than in the range of $5.3-27 \mathrm{mmol} \mathrm{dm}^{-3}$ (Zone 2) (Fig. 1b). On the other hand, $\left|\Delta \mathrm{H}_{\mathrm{g}}\right|$ dropped three times faster in Zone 1 than in Zone 2. The linear relationships between transition enthalpy and surfactant concentration are given by Eqs. (6)-(9) with $\mathrm{C}_{\mathrm{SSL}}$ in $\mathrm{mmol} \mathrm{dm}^{-3}$, the slope in $\mathrm{J} \mathrm{dm}^{3} \mathrm{~g}^{-1} \mathrm{~mol}^{-1}$, and the ordinate in $\mathrm{J} \mathrm{g}^{-1}$.

Melting

Zone1 $\Delta H=-3291 C_{S S L}+35.5 \mathrm{r}=0.9940$

Zone2 $\Delta H=-453 C_{S S L}+20.2 \quad \mathrm{r}=0.9735$

Gelling

Zone1 $\Delta H=-1987 C_{S S L}+34.1 \mathrm{r}=0.9903$

Zone2 $\Delta H=-663 C_{S S L}+25.9 \mathrm{r}=0.9763$

These variations show that the surfactant had a significant impact on the melting process, and the behavior shown in Fig. 1a and b can be interpreted as the result of a lower degree of association between $\mathrm{k}$ - carrageenan molecules. This action suggests the existence of a less dense aggregation leading to the destabilization of the $\kappa$-carrageenan gel network.

The melting process is noticeably affected by the surfactant, and significant changes occur below $5.3 \mathrm{mmol} \mathrm{dm}^{-3}$. The differences between melting and gelation temperatures can be explained by the aggregation of doubles helices. It is evident that gelation in the presence of $\mathrm{KCl}$ is less affected by SSL, perhaps due to the cooperative nature of carrageenan gelation but also to the mobility of the SSL molecules at the gelation temperature which improves the formation of the network. Besides, the addition of surfactant decreases progressively the thermal hysteresis which means less aggregation of helices. It has been shown that the gradual addition of glycerol, erythritol, xylitol, sorbitol, maltitol and carbohydrates like ribose, xylose, mannose, galactose, fructose, maltose and sucrose to $\mathrm{\kappa}$-carrageenan and $25 \mathrm{mmol} \mathrm{dm}^{-3} \mathrm{KCl}$, increased gelation temperatures but decreased the absolute values of $\Delta \mathrm{H}_{\mathrm{g}}$ (Gekko et al., 1987). The authors attributed this unusual behavior to polymer-solvent interactions because in general, absolute values of $\Delta \mathrm{H}_{\mathrm{g}}$ increase with the increment in $\mathrm{KCl}$ and other salts concentration. Changes in polymer-solvent interactions modify electrostatic, hydrophobic and hydrogen bond interactions of the $\kappa$-carrageenan network, and therefore its physicochemical properties (Gekko et al., 1987).

\subsubsection{Behavior in the presence of SSL without $\mathrm{KCl}$}

The thermal behavior of $\kappa$-carrageenan, without added $\mathrm{KCl}$, in the 
Version définitive du manuscrit publiée dans / Final version of the manuscript published in :

Carbohydrate Polymers (2018), Vol. 193, p. 289-297, DOI: 10.1016/j.carbpol.2018.04.002

Journal homepage : http://www.elsevier.com/locate/carbpol
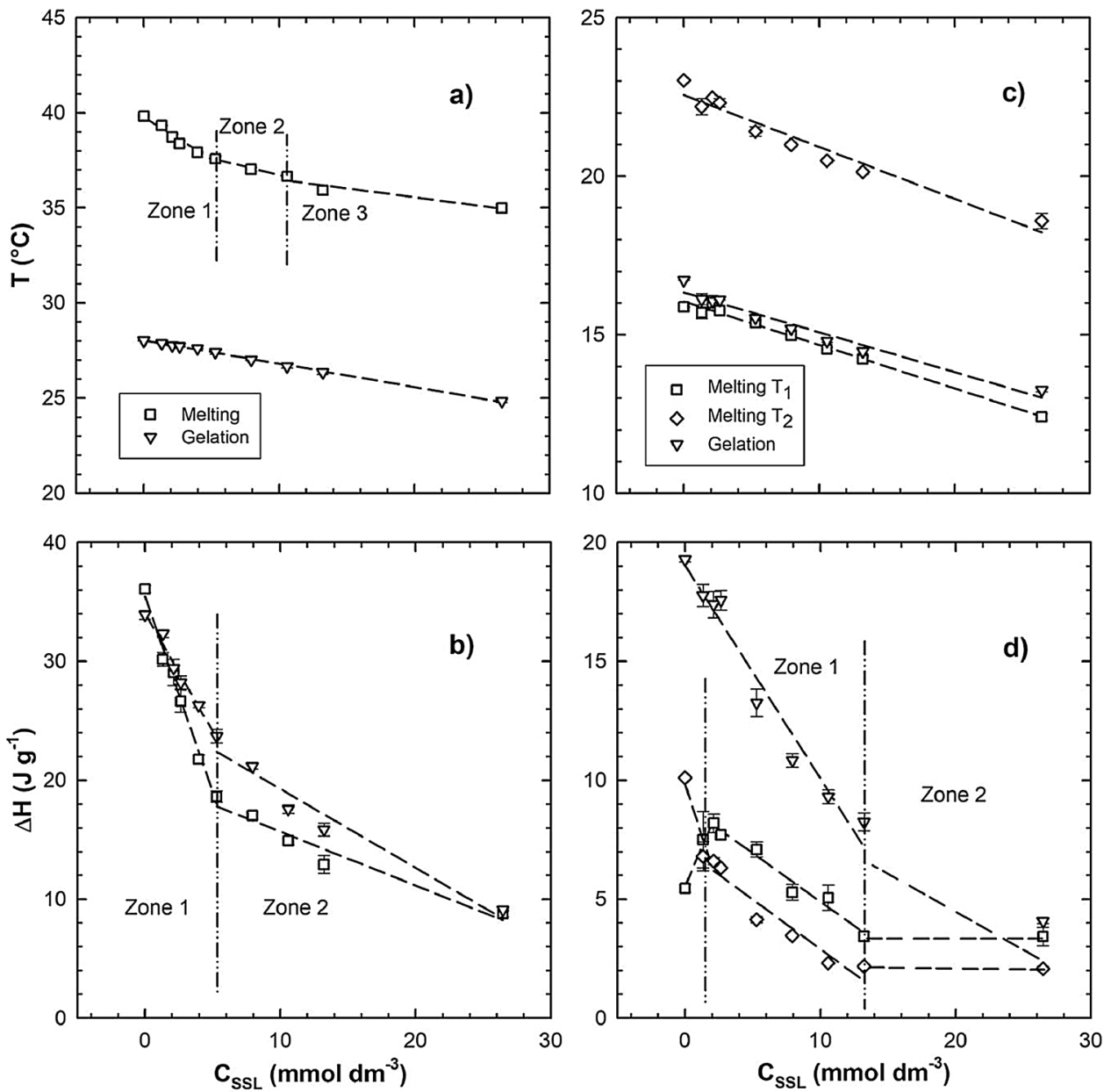

Fig. 1. Variation with SSL concentration of transition temperatures and enthalpies of $0.5 \%(\mathrm{w} / \mathrm{w}) \mathrm{\kappa}$-carrageenan gels with $13 \mathrm{mmol} \mathrm{dm}^{-3} \mathrm{KCl}$, (a), (b), respectively, and without $\mathrm{KCl}$, (c), (d), respectively. Melting (squares and diamonds), gelation (inverted triangles).

presence of SSL was similar to that of gels. There was a reduction in transition temperatures and enthalpies as in gels as shown in Fig. 1c and d, respectively. However, two transition peaks, (not shown), were observed on melting, in all the mixtures. The first peak, designated here as Melting $\mathrm{T}_{1}$, can be attributed to disaggregation of double helices and the second, Melting $\mathrm{T}_{2}$, to the unwinding of double helices to separate coils. Double helices exist as aggregates when the ionic concentration, $\mathrm{C}_{\mathrm{T}}$, of $\mathrm{K}^{+}$counterions is higher than the critical concentration $\mathrm{C}^{*}$. For $\mathrm{\kappa}-$ carrageenan, $\mathrm{C}^{*}=7.1 \mathrm{mmol} \mathrm{dm}{ }^{-3}$ (Rochas \& Rinaudo, 1984). $\mathrm{C}_{\mathrm{T}}$ for the solutions analyzed here was calculated from the concentration of $\mathrm{K}^{+}$ions, obtained by atomic absorption, in the samples of $\mathrm{\kappa}$-carrageenan and SSL. The values are between 14.35 and $14.67 \mathrm{mmol} \mathrm{dm}^{-3}$ without SSL and with the maximum SSL concentration, respectively, due to the intrinsic potassium content of the samples. On the other hand, for an ionic concentration of $5 \mathrm{mmol} \mathrm{dm}^{-3} \mathrm{KCl}$, the amount of helical dimmers and single helices was estimated to be 35 and $65 \%$, respectively (Rochas and Landry, 1987). Considering our atomic absorption data, the ionic concentration in a $0.5 \%(\mathrm{w} / \mathrm{w}) \kappa$-carrageenan solution is $7.9 \mathrm{mmol} \mathrm{dm}{ }^{-3} \mathrm{~K}^{+}$. These facts mean that in all the $\mathrm{\kappa}$-carrageenan solutions, aggregates and double helices can coexist.

The presence of these conformations, i.e., double helices and their aggregates, explains the two transitions on heating. Moreover, as indicated in Section 2, the commercial sample of $\kappa$-carrageenan used in this work was not purified. The appearance of two transition peaks could also be due to the possible presence of 1 -carrageenan as a minor component. However, NMR analysis (data not shown) showed $93 \% \mathrm{~K}$ carrageenan and 7\% 1 -carrageenan in the sample. Therefore, the contribution of 1-carrageenan was considered marginal, since in the solutions its concentration is lower than $0.04 \%$.

The effect of SSL concentration on the transition temperatures followed the same general trend for melting and gelation. In the entire concentration range, $0-27 \mathrm{~mol} \mathrm{dm}^{-3}$, there was a single-slope decrease. The corresponding equations with the same units as (2-5) are:

Melting $T_{1} \quad T_{m_{1}}=-137 C_{S S L}+16.0 \mathrm{r}=0.9938$

MeltingT $T_{m_{2}}=-164 C_{S S L}+22.6 \quad \mathrm{r}=0.9740$

Gelling $T_{g}=-125 C_{S S L}+16.3 \mathrm{r}=0.9808$

The addition of SSL had a more significant effect on gelation because $\Delta \mathrm{H}_{\mathrm{g}}$ decreased twice faster than each $\Delta \mathrm{H}_{\mathrm{m}}$. Changes in the enthalpies of gelation and melting transitions did not occur over the same SSL concentration range; $0-13 \mathrm{mmol} \mathrm{dm}^{-3}$ for gelation, 2.1-13 $\mathrm{mmol} \mathrm{dm}^{-3}$ for melting (Fig. 1d, Zone 1 and before). Below $2.1 \mathrm{mmol} \mathrm{dm}^{-3}$, Fig. 1d, before zone 1, the behavior of enthalpy for both melting processes was different. For Melting $T_{1}$, enthalpy increased, but for Melting $\mathrm{T}_{2}$ there was a reduction. Eqs. (13)-(15) show the relationships between enthalpy and SSL concentration with the same units as in Eqs. (6)-(9):

Melting $T_{1} \quad \Delta H=-407 C_{S S L}+9.0 \quad \mathrm{r}=0.9849$

Melting $T_{2} \quad \Delta H=-417 C_{S S L}+7.1 \quad \mathrm{r}=0.9612$

Gelling $\Delta H=-896 C_{S S L}+19.3 \mathrm{r}=0.9831$

From all these results, modification of the conformation of $\kappa$-carrageenan in gels and solutions by SSL is evident regardless of the 


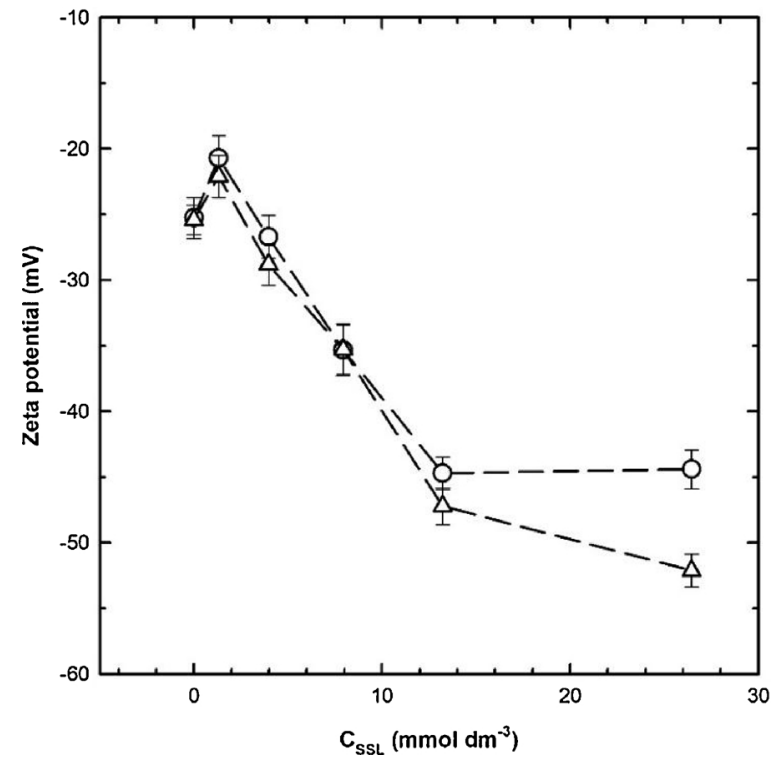

Fig. 2. Variation of the zeta potential of $0.5 \%(\mathrm{w} / \mathrm{w}) \mathrm{\kappa}$-carrageenan solutions with different SSL concentrations at $20^{\circ} \mathrm{C}$, without $\mathrm{KCl}$ (triangles) and with $13 \mathrm{mmol} \mathrm{dm}^{-3} \mathrm{KCl}$ (circles).

differences in thermal behavior between these systems. In this way, the SSL changes the spatial arrangement of $\kappa$-carrageenan. This phenomenon can be explained by the occurrence of hindrance caused by SSL in both systems. The aggregation of $\kappa$-carrageenan double helices is hindered by SSL, which explains the decrease of the melting enthalpy; but, over a specific surfactant concentration, surfactant molecules can aggregate causing a drop of melting enthalpy to a lesser extent than below such level.

Another possibility to explain the behavior of $\kappa$-carrageenan in the presence of SSL is the existence of electrostatic repulsion between both components as they are negatively charged. This effect occurs in solutions and gels because negative charges are not entirely screened by the positive charges of the counterions (Fig. 2).

Negative charges are in excess, either with or without $\mathrm{KCl}$, and the addition of SSL increases the negative charge density. However, this behavior tends to be stable for high SSL concentrations $\left(13 \mathrm{mmol} \mathrm{dm}^{-3}\right)$, probably due to aggregation of SSL molecules into micelle-like structures. The overall negative charge density is higher without $\mathrm{KCl}$ than with the salt, because of the screening effect of potassium ions. The combination of hindrance and electrostatic repulsion could explain the behavior differences between solutions and gels. In both systems, a decrease of enthalpies and transition temperatures occurs. However, in the solutions, the decline is continuous throughout the range of concentrations, while in the gels it happens above $5.3 \mathrm{mmol} \mathrm{dm}^{-3}$ SSL.

\subsection{Size, molar mass and conformation in solution}

Table 1 shows the size, molar mass, and dispersity of $\kappa$-carrageenan and its mixtures with SSL, using $\mathrm{NaCl}$ as an eluant. The molar mass of $3.08 \cdot 10^{5} \mathrm{~g} \mathrm{~mol}^{-1}$ found for $\kappa$-carrageenan without surfactant agrees with those reported on other samples in $100 \mathrm{mmol} \mathrm{dm}^{-3} \mathrm{NaCl}$ (Wittgren, Borgström, Piculell, \& Wahlund, 1998; Bourgoin et al., 2008). The molar mass and the radius of gyration increase clearly with SSL concentration. These results suggest that a change in the aggregation state of $\kappa$-carrageenan macromolecules occurs, as they appear more prominent in the mixtures with SSL, especially for the highest surfactant concentration.

This phenomenon is probably due to polymer-surfactant interactions. These data show the same general trend than the one observed in separate mixtures of bovine serum albumin (BSA) with sodium dodecyl sulfate (SDS), dodecyl trimethylammonium bromide (DTAB) and polyoxyethylene 8 lauryl ether (C12E8), which are anionic, cationic and nonionic surfactants, respectively. That is to say, the increase in the hydrodynamic radius of BSA compared to the hydrodynamic radii of the BSA-surfactants complexes, when the surfactant concentration increased. Such behavior has been attributed to cooperative binding of surfactants, which means that binding of one ligand enhances the affinity of the protein for subsequent ligands (Valstar, Almgren, Brown \& Vasilescu, 2000). Light scattering has also been used to study the behavior of individual blends of a capsular anionic bacterial polysaccharide with the cationic surfactants benzyl dimethyl-n-hexadecyl ammonium chloride (BDHAC), cetyltrimethylammonium bromide (CTAB), cetyl pyridinium chloride (CPC) and dodecyl pyridinium chloride (DPC). The variation of the hydrodynamic radius with surfactant concentration exhibited a maximum. This behavior was attributed to aggregation derived from polysaccharide-surfactant complexation by electrostatic attraction between both components. Beyond the maximum, the decrease in hydrodynamic radius was explained by coiling up of the polysaccharide resulting from its charge neutralization (Dasgupta, Nath, Manna, Mitra, \& Panda, 2014).

The dispersities of $\kappa$-carrageenan without surfactant and with $0.004 \%$ SSL were similar $(\approx 1.4)$. However, for the maximum SSL level, a higher dispersity was obtained, indicating a broader size distribution, also shown in the cumulative molar mass distribution (Fig. 3), which highlights a considerable proportion of high molar masses in the solution with $0.017 \%$ SSL.

This result could be due to macromolecule association caused by polymer-surfactant interactions. It is also in line with the lower elution recovery observed for $\kappa$-carrageenan with the maximum SSL level $(67 \%$ instead of 83 and $89 \%$ for $\kappa$-carrageenan without SSL and with the minimum SSL level, respectively), which could correspond to the retention of the major macromolecular structures in the AF4 channel.

Table 1 also includes values of the Flory exponent $(\nu)$, calculated by linear regression of the $\log$ - $\log$ plot of $\mathrm{R}_{\mathrm{Gi}}$ versus $\mathrm{M}_{\mathrm{i}}$, according to $\mathrm{R}_{\mathrm{Gi}}=\mathrm{K} \mathrm{M}_{\mathrm{i}}{ }^{\nu}$, where $\mathrm{K}$ is a constant. For a swollen linear polymer, $\nu$ is around $3 / 5$. The exponent is used to determine whether the polymer is in a suitable solvent. In such case, polymer-solvent interactions are more favorable than polymer-polymer interactions (Rubinstein \& Colby, 2003). In $\kappa$-carrageenan solutions without SSL, polysaccharide chains are in a suitable solvent $(\nu=0.60)$. The addition of surfactant decreased the value of $\nu$ to about 0.50 for both conditions. For this value of the Flory exponent, theta conditions exist, i.e., the polysaccharide is on the border between good and poor solvent. In the theta state, the solvent has a minimal solvation effect on the polymer molecules, i.e., the polymer is becoming insoluble ( $\mathrm{Su}, 2013)$.

These results suggest a change in polymer-solvent interactions

Table 1

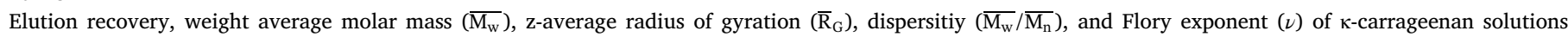
obtained by AF4-MALLS.

\begin{tabular}{|c|c|c|c|c|c|c|}
\hline к-carrageenan (\%) & SSL (\%) & Elution recovery (\%) & $\overline{\boldsymbol{M}_{\boldsymbol{w}}} 10^{-5}\left(\mathrm{~g} \mathrm{~mol}^{-1}\right)$ & $\overline{\boldsymbol{R}_{G}}(\mathrm{~nm})$ & $\overline{M_{w}} / \overline{M_{n}}$ & $\nu$ \\
\hline 0.15 & 0.0 & 83 & $3.08 \pm 0.16$ & $56 \pm 2.1$ & $1.4 \pm 0.01$ & $0.60 \pm 0.02$ \\
\hline 0.05 & 0.004 & 89 & $4.64 \pm 0.13$ & $75 \pm 4.4$ & $1.3 \pm 0.18$ & $0.50 \pm 0.02$ \\
\hline 0.05 & 0.017 & 67 & $12.92 \pm 1.03$ & $157 \pm 20.3$ & $2.9 \pm 0.74$ & $0.48 \pm 0.02$ \\
\hline
\end{tabular}


Journal homepage : http://www.elsevier.com/locate/carbpol

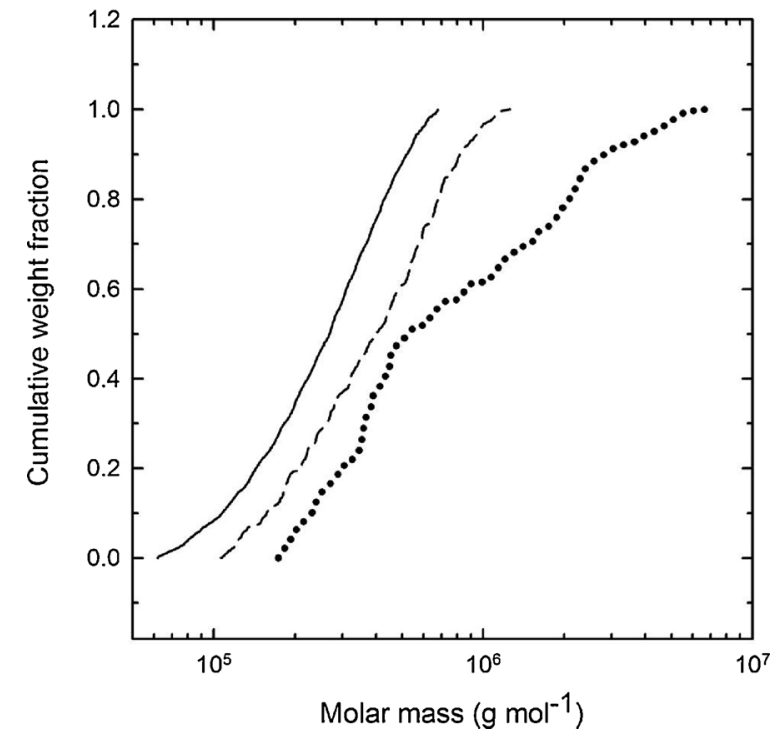

Fig. 3. Cumulative molar mass distributions obtained by AF4-MALLS of $0.5 \%$ $(\mathrm{w} / \mathrm{w}) \mathrm{\kappa}$-carrageenan solutions without SSL (continuous line), with 0.004 and $0.017 \%$ SSL (dashed and dotted line, respectively).

probably due to electrostatic interactions between $\kappa$-carrageenan and SSL, which can cause compaction of polymer chains and therefore a modification in their conformation.

\subsection{Rheological behavior}

\subsubsection{Gels}

Frequency sweeps for $\kappa$-carrageenan gels with different SSL concentrations are shown in Fig. 4a. The slopes of G' and G" were found to increase with SSL concentration; $\alpha=0.032-0.078$ with $r>0.9669$, and $\beta=0.125-0.167$ with $r>0.9109$, respectively. This variation means that both dynamic moduli were more frequency dependent as SSL concentration increased. Therefore, the presence of SSL intensified the viscous character of $\kappa$-carrageenan gels, showing a less organized network. This effect is also evidenced by the disappearance of the plateau in G' at low frequency for the highest SSL concentration.

Also, the elastic character of the gels decreased, i.e., the loss angle, $\delta$, increased from 3.7 to $8.4^{\circ}$ for $27 \mathrm{mmol} \mathrm{dm}^{-3}$ SSL. These features can be observed in Fig. $4 \mathrm{~b}$. For concentrations below $4 \mathrm{mmol} \mathrm{dm}^{-3}$, G' at $1 \mathrm{rad} \mathrm{s}^{-1}$ decreased as SSL concentration increased. Above this concentration, changes were not significant. G" exhibited the same behavior for $\mathrm{\kappa}$-carrageenan without SSL and with $1.3 \mathrm{mmol} \mathrm{dm}^{-3}$. However, for 13 and $27 \mathrm{mmol} \mathrm{dm}^{-3}$ SSL, G" increased with the frequency which means an accentuation of the viscous behavior of the systems.

\subsubsection{Solutions}

The $\kappa$-carrageenan solutions exhibited a typical macromolecular behavior (Fig. 5a), i.e., G" was greater than G' and both moduli were highly dependent on frequency (Doublier, Garnier \& Cuvelier, 2016). As in the gels, G' and G" decreased as SSL concentration increased, but for the highest level, $27 \mathrm{mmol} \mathrm{dm}^{-3}$, both moduli increased. The evolution of the apparent viscosity of $\kappa$-carrageenan solutions, Fig. 6a, was like that of the dynamic moduli. All solutions exhibited shear-thinning behavior, i.e., the apparent viscosity decreased as shear rate increased. It is well known that the viscosity of polyelectrolyte solutions decreases with the increment of salt concentration because there is a compaction of the polymer chain due to the screening of the electrostatic repulsions between charges along the chain by the counterions (Wyatt, Gunther, \& Liberatore, 2011). This effect explains the reduction of the apparent viscosity with the increment of SSL concentration in agreement with the light scattering results. Increases in G', G” and $\eta$ for the $\kappa$-carrageenan
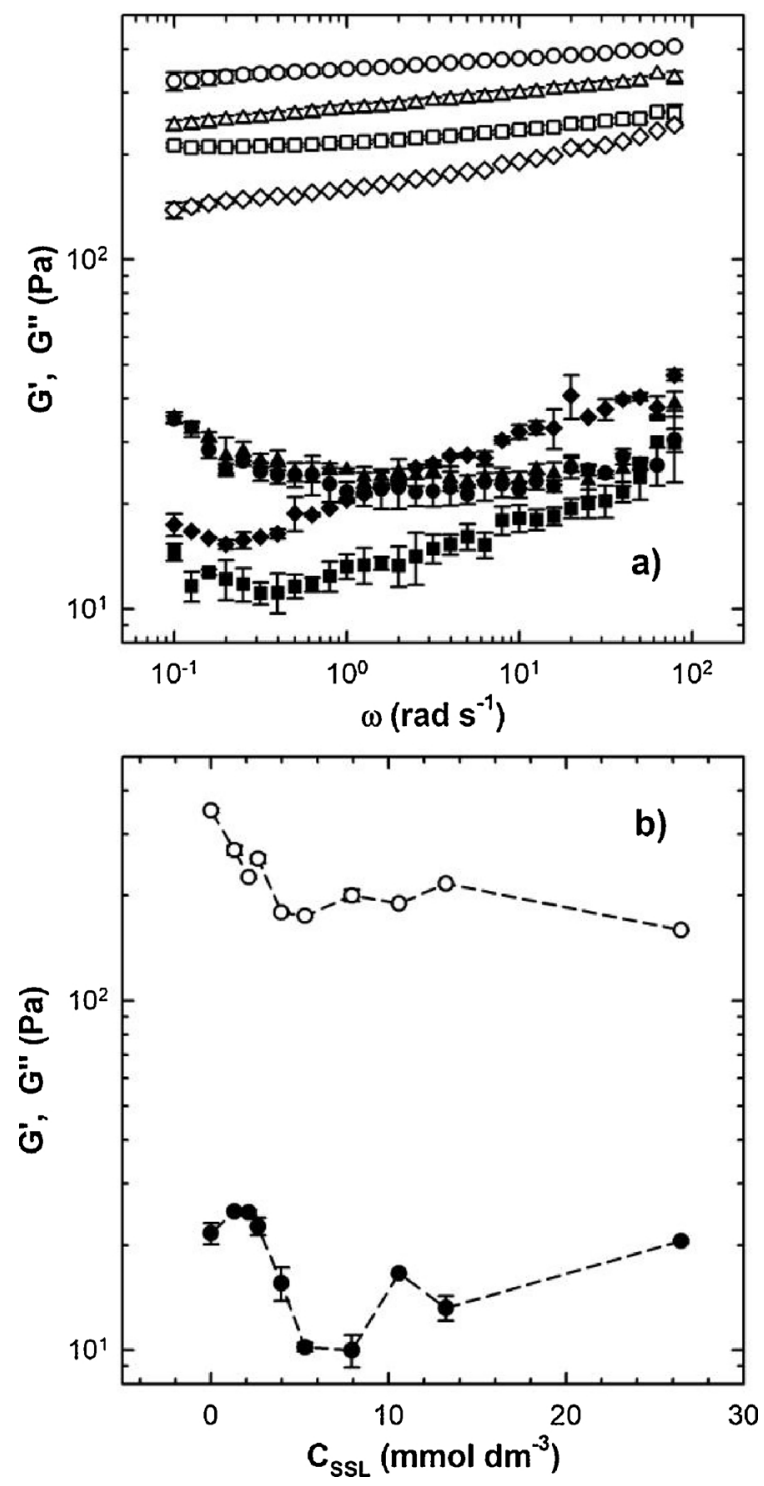

Fig. 4. a) Variation of G' (open symbols) and G" (filled symbols) with angular frequency $(\omega)$ of $0.5 \%(\mathrm{w} / \mathrm{w}) \mathrm{\kappa}$-carrageenan gels with $13 \mathrm{mmol} \mathrm{dm}{ }^{-3} \mathrm{KCl}$, and without SSL (circles), $1.3 \mathrm{mmol} \mathrm{dm}^{-3}$ (triangles), $13 \mathrm{mmol} \mathrm{dm}^{-3}$ (squares), and $27 \mathrm{mmol} \mathrm{dm}{ }^{-3}$ (diamonds) at $25^{\circ} \mathrm{C}$; b) Variation of G' and G" with SSL concentration at $\omega=1 \mathrm{rad} \mathrm{s}^{-1}$ and $25^{\circ} \mathrm{C}$.

solution with $27 \mathrm{mmol} \mathrm{dm}^{-3}$ SSL are due to the surfactant concentration. Indeed, the viscosity of the SSL solution with the same concentration is $282 \mathrm{mPa} \cdot \mathrm{s}$ at $25^{\circ} \mathrm{C}$ and $\dot{\gamma}=1 \mathrm{~s}^{-1}$, although $\mathrm{\kappa}$-carrageenan had a lower viscosity from $51 \mathrm{mPa}$.

The rheological results coincide with thermal effects, since the addition of SSL to $\kappa$-carrageenan gels and solutions modifies the polysaccharide behavior. The presence of at least two zones with different responses is observed with both techniques. Thus, two effects are proposed for these differences. In the first zone, electrostatic repulsions would predominate, while in the second zone hindrance caused by SSL micellization could also be present.

\subsection{Microstructure of gels}

The AFM microstructures of SSL, $\kappa$-carrageenan gels and its mixtures are shown in Fig. 7. Spherical vesicles can be observed in the SSL solution (Fig. 5a). These structures are similar but smaller than those observed by differential interference contrast light microscopy in $0.1 \%$ SSL (Bezelgues, Serieye, Crosset-Perrotin \& Leser, 2008). The lower 
Journal homepage : http://www.elsevier.com/locate/carbpol
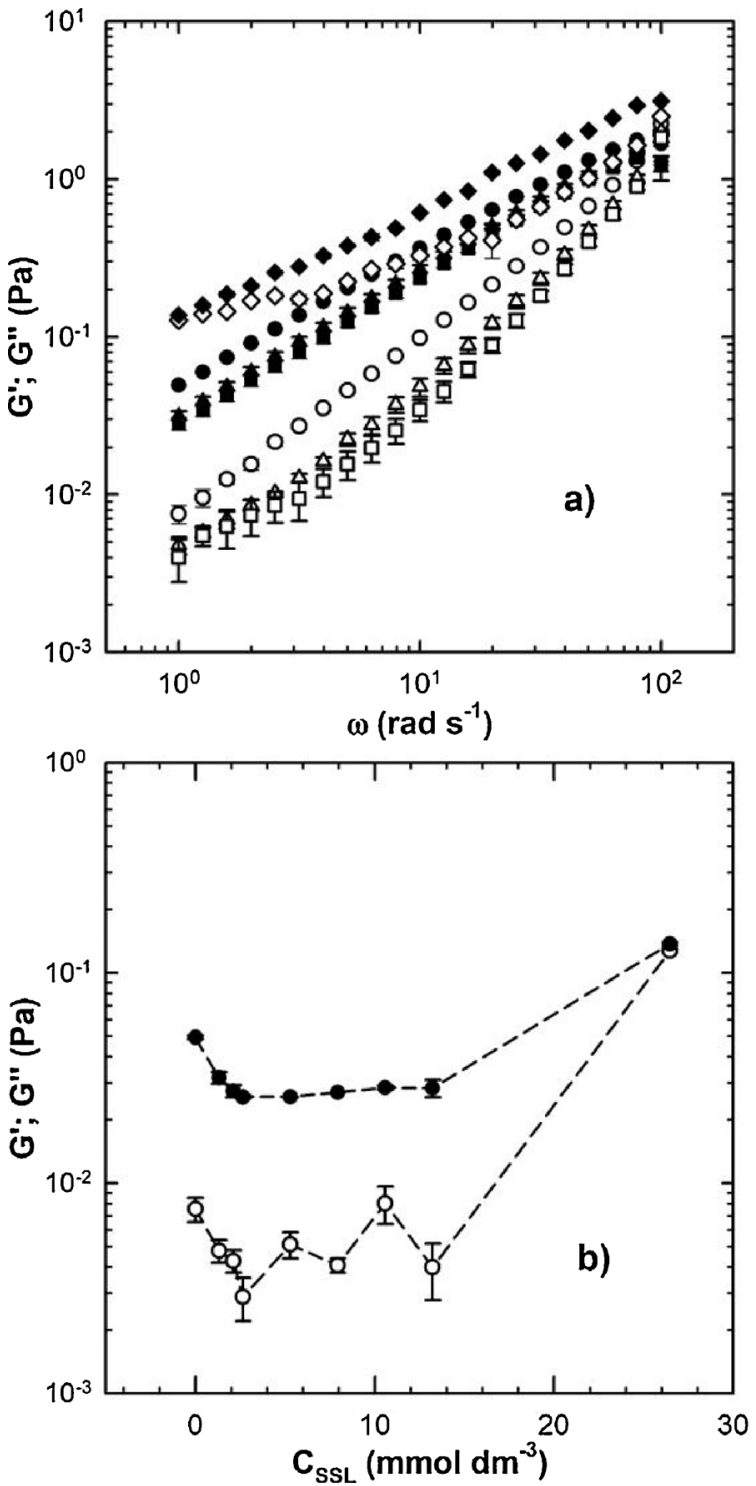

Fig. 5. a) Variation of G' (open symbols) and G" (filled symbols) with frequency of $0.5 \%(\mathrm{w} / \mathrm{w}) \mathrm{k}$-carrageenan solutions without SSL (circles), $1.3 \mathrm{mmol} \mathrm{dm}^{-3}$ SSL (triangles), $13 \mathrm{mmol} \mathrm{dm}^{-3}$ SSL (squares), and $27 \mathrm{mmol} \mathrm{dm}^{-3}$ SSL (diamonds) at $25^{\circ} \mathrm{C}$, and b) Variation of G' and G" with SSL concentration at $\omega=1 \mathrm{rad} \mathrm{s}^{-1}$ and $25^{\circ} \mathrm{C}$.

surfactant concentration used in our study could explain the differences. The black areas in the image are air holes left by water evaporated before the observations. This phenomenon also explains the proximity between the structures. The fibrous structure of $\kappa$-carrageenan with $13 \mathrm{mmol} \mathrm{dm}^{-3} \mathrm{KCl}$ is shown in Fig. 7b. This salt concentration causes incipient side-by-side aggregation like that observed in $\kappa$-carrageenan solutions without $\mathrm{KCl}$, but with a higher $\mathrm{\kappa}$-carrageenan concentration $\left(25 \mu \mathrm{gL}^{-1}\right.$ ) (Sokolova et al., 2013). Despite this difference, a network was formed, and gelation occurred, which is consistent with the rheological data shown in 3.3.1. The addition of SSL leads to segregation between both components (Fig. 7c), may be caused by the electrostatic repulsions. A higher SSL concentration (Fig. 7d) originated structures resembling to those obtained without surfactant. However, areas with segregation were still observed. It is evident that the addition of SSL to $\kappa$-carrageenan modifies its space arrangement, since surfactant alters the formation of the $\kappa$-carrageenan network. SSL concentration is a crucial factor for these modifications to occur, and the interactions between SSL and $\kappa$-carrageenan depend on the amount
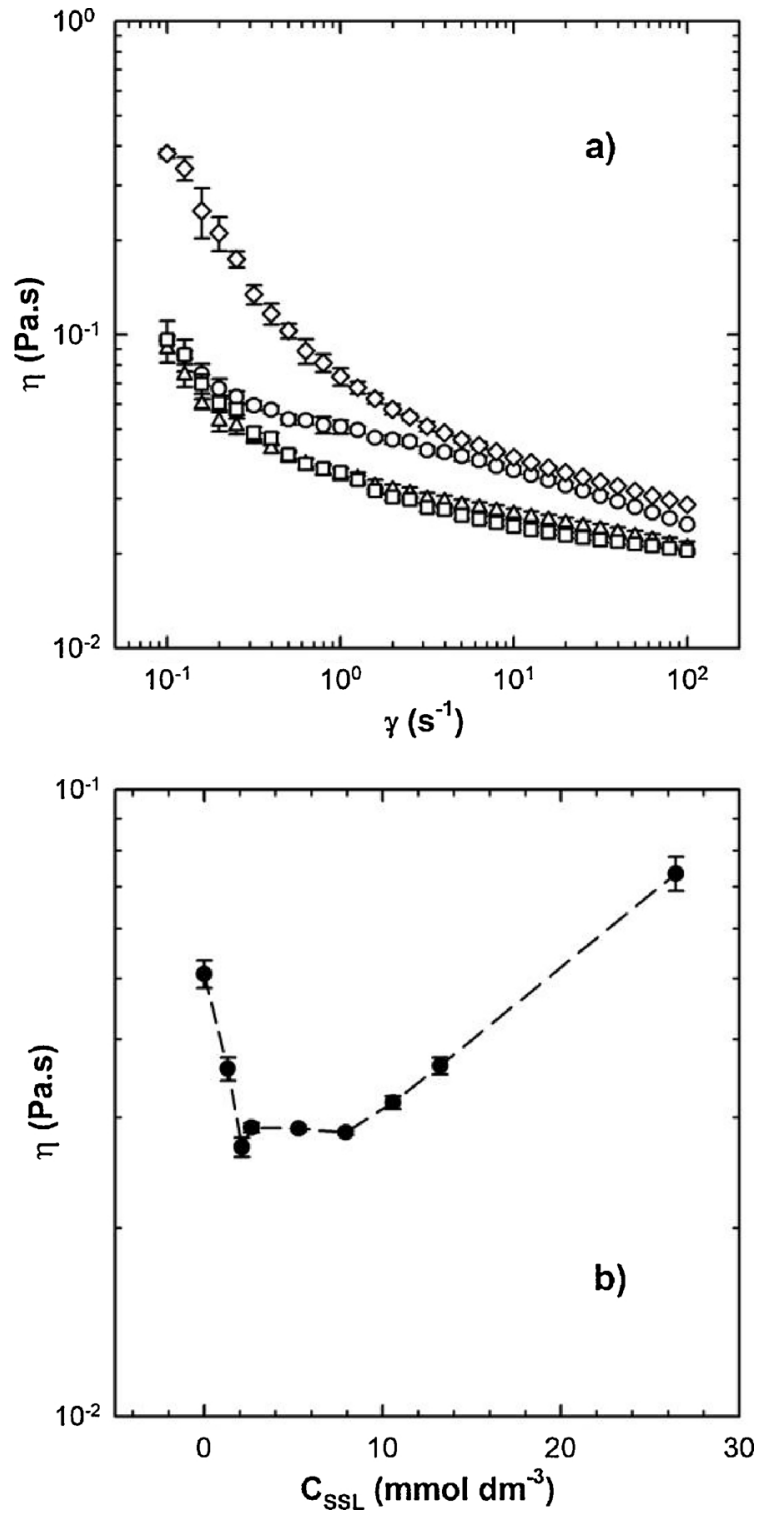

Fig. 6. a) Viscosity flow curves of $0.5 \%(w / w) \kappa$-carrageenan solutions without SSL (circles), $1.3 \mathrm{mmol} \mathrm{dm}{ }^{-3} \mathrm{SSL}$ (triangles), $13 \mathrm{mmol} \mathrm{dm}^{-3}$ SSL (squares) and $27 \mathrm{mmol} \mathrm{dm}^{-3} \mathrm{SSL}$ (diamonds) at $25^{\circ} \mathrm{C}$, and b) Variation of viscosity with SSL concentration at $\dot{\gamma}=1 \mathrm{~s}^{-1}$ and $25^{\circ} \mathrm{C}$.

of SSL. When SSL concentration in the mixture was $13 \mathrm{mmol} \mathrm{dm}^{-3}$, a noticeable segregation occurred. However, when the level increased to $27 \mathrm{mmol} \mathrm{dm}^{-3}$, this phenomenon was reduced. This behavior agrees with the thermal and rheological behaviors. On the other hand, the cationic surfactant cetyl(trimethyl) ammonium bromide (CTAB) gives rise to a denser cross-linking of the double helices leading to a denser $\mathrm{K}$ carrageenan network. The interaction between $\mathrm{CTAB}$ and $\kappa$-carrageenan stabilizes the helices of the polysaccharide even in the absence of $\mathrm{K}^{+}$ions (Kolesov et al., 2008). The behavior of $\kappa$-carrageenan with SSL and CTAB is different because the former is negatively charged, while the latter has positive charges.

\section{Conclusions}

The addition of SSL to $\kappa$-carrageenan gels and solutions modified the conformation of the polysaccharide. The mixtures presented widespread but more compact conformations than the polysaccharide without surfactant. This alteration is due to hindrance of SSL molecules on $\kappa$-carrageenan chains and changes in polysaccharide-solvent 


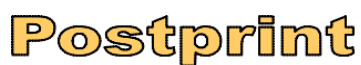

Version définitive du manuscrit publiée dans / Final version of the manuscript published in :

Carbohydrate Polymers (2018), Vol. 193, p. 289-297, DOI: 10.1016/j.carbpol.2018.04.002

Journal homepage : http://www.elsevier.com/locate/carbpol
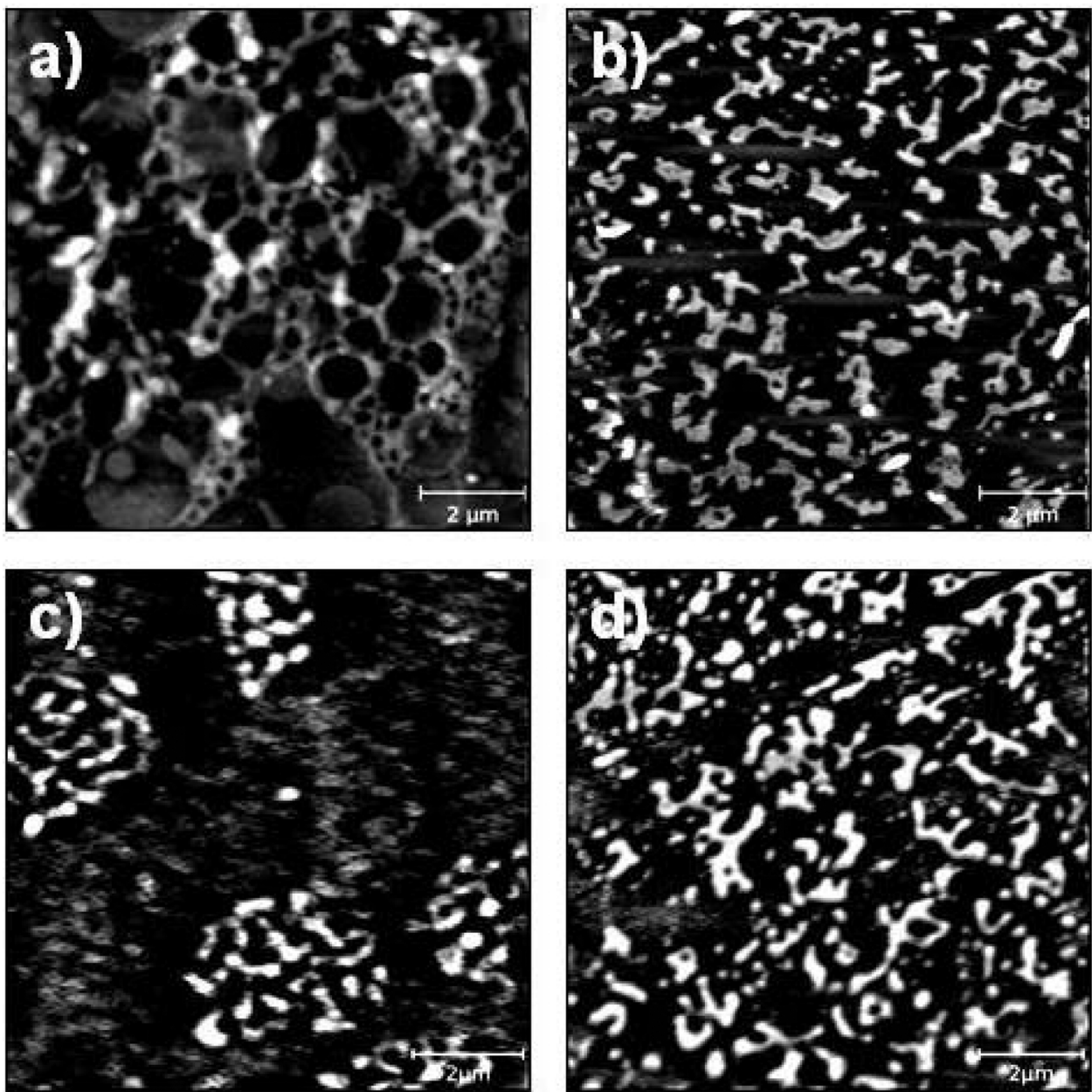

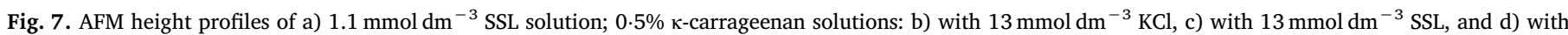
$27 \mathrm{mmol} \mathrm{dm}^{-3}$ SSL. All $\kappa$-carrageenan solutions were diluted to $20 \mu \mathrm{g} \mathrm{mL}^{-1}$ before cooling. Size $10 \times 10 \mu \mathrm{m}$.

interactions caused by electrostatic interactions between both components, which affect the thermal, rheological and conformational parameters. In general, a destabilization of $\kappa$-carrageenan conformation is suggested. This phenomenon explains the results obtained in this work.

\section{Acknowledgments}

The authors acknowledge DGAPA-UNAM for financing this work (Grant IN221915). Author Ortiz-Tafoya acknowledges CONACyT (Grant 211344) for Ph.D. scholarship and Programa de Maestría y Doctorado en Ingeniería-UNAM for additional financial support. Thanks are due to Mariana Ramirez-Gilly for assistance in rheological measurements. The authors thank IFMAS (French Institute of Biobased Materials) for the provision of the AF4-MALLS equipment. The support of Professor Ismael Bustos Jaimes with AFM, Dr. María M. MurilloMartínez with zeta potential, and Dr. Atilano Gutiérrez Carrillo with NMR experiments is greatly appreciated.

\section{References}

Bezelgues, J.-B., Seriye, S., Crosset-Perrotin, L., \& Leser, M. E. (2008). Interfacial and foaming properties of some food grade low molecular weight surfactants. Colloids and Surfaces A: Physicochemical and Engineering Aspects, 331, 56-62.

Bourgoin, A., Zablackis, E., \& Poli, J. B. (2008). Characterization of $\alpha$-carrageenan solution behavior by field-flow fractionation and multiangle light scattering. Food Hydrocolloids, 22(8), 1607-1611.

Boutte, T., \& Skogerson, L. (2004). Stearoyl-2-lactylates and oleoyl lactylates. In R. J. Whitehurst (Ed.). Emulsifiers in food technology (pp. 206-225). Oxford, UK: Blackwell Publishing Ltd.

Bouyer, E., Mekhloufi, G., Rosilio, V., Grossiord, J.-L., \& Agnely, F. (2012). Proteins, polysaccharides, and their complexes used as stabilizers for emulsions: Alternatives to synthetic surfactants in the pharmaceutical field? International Journal of Pharmaceutics, 436(1-2), 359-378

Chiappisi, L., \& Gradzielski, M. (2015). Co-assembly in chitosan-surfactant mixtures: Thermodynamics, structures, interfacial properties and applications. Advances in Colloid and Interface Science, 220, 92-107.

Dasgupta, S., Nath, R. K., Manna, K., Mitra, A., \& Panda, A. M. (2014). Physico-chemica studies on the interaction of bacterial polysaccharide-surfactant aggregates with special reference to their hydrodynamic behavior. Journal of Oleo Science, 63(10), 1063-1075.

De Ruiter, G. A., \& Rudolph, B. (1997). Carrageenan biotechnology. Trends in Food Science \& Technology, 8, 389-395.

Doublier, J.-L., Garnier, C., \& Cuvelier, G. (2016). Gums and hydrocolloids: Functional aspects. In A.-C. Eliasson (Ed.). Carbohydrates in food (pp. 285-332). Boca Raton, FL: CRC Taylor \& Francis.

Gekko, K., Mugishima, H., \& Koga, S. (1987). Effects of sugars and polyols on the sol-gel transition of $\kappa$-carrageenan: Calorimetric study. International Journal of Biological Macromolecules, 9, 146-152.

Grant, J., Cho, J., \& Allen, C. (2006). Self-assembly and physicochemical and rheological properties of a polysaccharide-surfactant system formed from the cationic biopolymer chitosan and nonionic sorbitan esters. Langmuir, 22(9), 4327-4335.

Grigoriev, D. O., Leser, M. E., Michel, M. \& Miller, R. (2006). Component separation in spread sodium stearoyl lactylate (SSL) monolayers induced by high surface pressure. Colloids and Surfaces A: Physicochemical and Engineering Aspects, 286, 57-61.

Grigoriev, D. O., Leser, M. E., Michel, M., \& Miller, R. (2007). Mixed micelles as delivery systems for enhanced emulsifier adsorption at the air/water interface: Sodium stearoyl lactylate (SSL)/Tween 80 solutions. Colloids and Surfaces A: Physicochemical and Engineering Aspects, 301, 158-165.

Kogej, K. (2008). Binding of cation surfactants by kappa, iota, and lambda carrageenans in aqueous solution in the presence of sodium chloride. Acta Chimica Slovenica, 55, 985-991.

Kolesov, D. V., Grigor'ev, T. E., Gavrilko, D. Y., Makhaeva, E. E., Yaminskii, I. V., \& Khokhlov, A. R. (2008). AFM study of the structuration of an ionic surfactant and phenylalanine with $\kappa$-carrageenan. Protection of Metals, 44(5), 447-451.

Núñez-Santiago, M. C., \& Tecante, A. (2007). Rheological and calorimetric study of the sol-gel transition of $\kappa$-carrageenan. Carbohydrate Polymers, 69, 763-773. 
Version définitive du manuscrit publiée dans / Final version of the manuscript published in :

Carbohydrate Polymers (2018), Vol. 193, p. 289-297, DOI: 10.1016/j.carbpol.2018.04.002

\section{Journal homepage : http://www.elsevier.com/locate/carbpol}

Rochas, C., \& Landry, S. (1987). Molecular organization of kappa carrageenan in aqueous solution. Carbohydrate Polymers, 7, 435-447.

Rochas, C., \& Rinaudo, M. (1984). Mechanism of gel formation in $\kappa$-carrageenan. Biopolymers, 23, 735-745.

Rolland-Sabaté, A., Colonna, P., Mendez-Montealvo, M. G., \& Planchot, V. (2007). Branching features of amylopectins and glycogen determined by asymmetrical flow field flow fractionation coupled with multiangle laser light scattering. Biomacromolecules, 8, 2520-2532.

Rolland-Sabaté, A., Guilois, S., Jaillais, B., \& Colonna, P. (2011). Molecular size and mass distributions of native starches using complementary separation methods: Asymmetrical flow field flow fractionation (A4F) and hydrodynamic and size exclusion chromatography (HDC-SEC). Analytical and Bioanalytical Chemistry, 399, 1493-1505.

Rubinstein, M., \& Colby, R. H. (2003). Polymer physics. Oxford, UK: Oxford University Press.

Sokolova, E. V., Chusovitin, E. A., Barabanova, A. O., Balagan, S. A., Galkin, N. G., \& Yermak, I. M. (2013). Atomic force microscopy imaging of carrageenans from red algae of Gigartinaceae and Tichocarpaceae families. Carbohydrate Polymers, 93, 458-465.

Su, W.-F. (2013). Principles of polymer design and synthesis. lectures notes in chemistry, Vol. 82. London: Springer.

Valstar, A., Almgren, M., Brown, W., \& Vasilescu, M. (2000). The interaction of bovine serum albumin with surfactants studied by light scattering. Langmuir, 16, 922-927.

Vinceković, M., Katona, J., Bujan, M., \& Sovilj, V. (2011). Interactions between dodecylammonium chloride and carrageenans in the semidilute regime. Colloids and Surfaces A: Physicochemical and Engineering Aspects, 384(1-3), 739-748.

Wittgren, B., Borgström, J., Piculell, L., \& Wahlund, K.-G. (1998). Conformational change and aggregation of kappa-carrageenan studied by flow field-flow fractionation and multiangle light scattering. Biopolymers, 45, 85-96.

Wyatt, N. B., Gunther, C. M., \& Liberatore, M. W. (2011). Increasing viscosity in entangled polyelectrolyte solutions by the addition of salt. Polymer, 52(11), 2437-2444.

Zinoviadou, K. G., Moschakis, T., Kiosseoglou, V., \& Biliaderis, C. G. (2011). Impact of emulsifier-polysaccharide interactions on the stability and rheology of stabilised oilin-water emulsions. Procedia Food Science, 1, 57-61. 